\title{
Correction to: Effect of microcapsules doping on DC flashover and trap level of self-healing epoxy resin composites
}

Muhammad Zeeshan Khan ${ }^{1, \star}$ (1), Aurang Zaib ${ }^{1}$, Asim Khan ${ }^{1}$, Muhammad Arshad Shehzad Hassan ${ }^{1}$, Umar Farooq ${ }^{1}$, and Zahir Javed Paracha ${ }^{1}$

${ }^{1}$ Department of Electrical Engineering and Technology, The University of Faisalabad, Faisalabad 38000, Punjab, Pakistan

Published online:

20 January 2021

(C) Springer Science+Business Media, LLC, part of Springer

Nature 2021

Correction to:

Journal of Materials Science: Materials in Electronics

https:/doi.org/10.1007/s10854-020-05017-8

In the original version of this article, unfortunately, one of the co-author names was published with incorrect spelling. The correct name should read as
"Muhammad Arshad Shehzad Hassan". This has been corrected by publishing this correction article. The original article has been corrected.

Publisher's Note Springer Nature remains neutral with regard to jurisdictional claims in published maps and institutional affiliations.

The original article can be found online at https:/ / doi.org/10.1007/s10854-020-05017-8.

Address correspondence to E-mail: Muhammad.zeeshan@tuf.edu.pk 